\title{
Stability analysis for yield and its attributing traits in advanced breeding lines of rabi sorghum (Sorghum bicolor (L.) Moench)
}

\author{
G. Girish ${ }^{\star *}$,S. B. Kiran ${ }^{2}$, R. Lokesh ${ }^{2}$, Vikas, V. Kulkarni ${ }^{3}$, V. Rachappa ${ }^{4}$, L. N. Yogesh ${ }^{5}$ and \\ A. M. Talwar ${ }^{6}$ \\ ${ }^{1}$ AICSIP, Agriculture Research Station, Gulbarga-585101, Karnataka, INDIA \\ ${ }^{2}$ Department of Genetics and Plant Breeding, Agriculture College, University of Agricultural Sciences, Raichur- \\ 584102, Karnataka, INDIA. \\ ${ }^{3}$ Main Agriculture Research Station Raichur-584102, Karnataka, INDIA \\ ${ }^{4}$ Department of Agricultural Entomology, Agriculture College, Gulbarga-585101,Karnataka, INDIA \\ ${ }^{5}$ Agriculture Research Station Hagari- 583138, Karnataka, INDIA \\ ${ }^{6}$ Agriculture Research Station Malnoor-585215, Karnataka, INDIA \\ *Corresponding author. E mail: girish.cowpea@gmail.com
}

Received: February 23, 2015; Revised received: October 10, 2015; Accepted: January 5, 2016

\begin{abstract}
An experiment was carried out involving twenty three advanced breeding lines along with two checks $M$ 35-1 and Muguthi during rabi season 2012-13 at four locations. Observations were recorded on 10 different characters viz., plant height $(\mathrm{cm})$, stem diameter $(\mathrm{cm})$, ear head length $(\mathrm{cm})$, ear head diameter $(\mathrm{cm})$, days to 50 per cent flowering, days to maturity, 100 seed weight $(\mathrm{g})$, fodder yield per plot $(\mathrm{kg})$, seed yield per plot $(\mathrm{kg})$, and lodging percentage. The pooled analysis of variance revealed that mean sum of squares due to genotypes was significant for ear head diameter, days to 50 per cent flowering, days to maturity and fodder yield, indicating presence of considerable amount of variability in the genotypes. The mean sum of square due to environment + (genotypes $x$ environment) was significant for plant height, ear head length $(\mathrm{cm})$, ear head diameter $(\mathrm{cm})$, days to 50 per cent flowering, fodder yield per plot $(\mathrm{kg})$, seed yield per plot $(\mathrm{kg})$, and lodging percentage characters except stem diameter, days to maturity and 100 seed yield. On the basis of stability parameters a four genotypes viz., GS-6 (2364 kg/ha), GS-16 (2454 kg/ha), GS-22(2775 kg/ha) and GS-23(2978 kg/ha) were found most stable over Gulbarga, Raichur, Bellary and Malnoor environments of Hyderabad Karnataka region.
\end{abstract}

Key words: Eberhart and Russel model, Genotypes, Regression, Sorghum, Stability

\section{INTRODUCTION}

Sorghum (Sorghum bicolor (L.) Moench) is one of the important food crops in the world. It is cultivated in many parts of Asia and Africa, in world over an area of $37.86 \mathrm{~m}$ ha with a production of $54.03 \mathrm{~m} \mathrm{t}$ and a productivity of $1430 \mathrm{~kg}$ per ha. While in India, it occupies an area of $6.23 \mathrm{~m}$ ha with a production of $60.06 \mathrm{~m} \mathrm{t}$ and productivity of $962 \mathrm{~kg}$ per ha. Karnataka is the second state after Maharashtra with regard to area coverage in India. In Karnataka, sorghum is grown over an area of 11.45 lakh ha with a production of 11.60 lakh $t$ and productivity is $1021 \mathrm{~kg}$ per ha (Anonymous, 2013; Kumar and Chopra, 2013). Hyderabad-Karnataka region covers an area of 6.9 lakh ha and production of 6.09 lakh tones with productivity $996 \mathrm{~kg} / \mathrm{ha}$ (Anonymous, 2010). Over the years due to global warming and climatic changes directed to reduce the productivity of many crops around the world. Its influence on sorghum also, farmers were cultivating long duration land races which results in low yielding. The non performance of farmer variety due to climate fluc- tuations requires stable variety, which perform better in this condition. In this connection genotype $\times$ environment interaction continuous to be a challenging issue among the plant breeders, geneticists and production agronomists who carry out crop performance trails across diverse environments. Consequently, to develop a variety with high yielding ability and consistency, precise attention should be given to the importance of stability performance for the genotypes under different environments and their interactions. The interaction between genotype and environment had an important impact on breeding for better varieties (Allard and Bradshaw, 1964). So that a considerable attention should be given to the effect of genotype- environment interaction in the plant breeding programs especially in the developing countries. Developing high yielding cultivars is mainly depending upon existing genetic variation among the germplasm under existing breeding programs. The relative performance of cultivars for quantitative traits such as yield and the other characters, which influence yield, vary from an environment to another. 
Table 1. Origin of 23 advanced lines of sorghum.

\begin{tabular}{|c|c|c|c|c|}
\hline S. N. & Lines & Pedigree & Region adapted & Kg/ha \\
\hline 1 & GS-1 & Kodikal-3 & North Karnataka & 2372 \\
\hline 2 & GS-2 & Chincholi-2 & North Karnataka & 2353 \\
\hline 3 & GS-3 & Mudbal-1 & North Karnataka & 2611 \\
\hline 4 & GS-4 & M X Niralkodi-10-14-2 & North Karnataka and Maharashtra & 2684 \\
\hline 5 & GS-5 & M X Niralkodi-9-14-1 & North Karnataka and Maharashtra & 2518 \\
\hline 6 & GS-6 & JP-1-5 & North Karnataka & 2364 \\
\hline 7 & GS-7 & M X Bommnahalli-4-2 & North Karnataka & 2303 \\
\hline 8 & GS-8 & M X Bommnahalli-4-3 & North Karnataka & 2597 \\
\hline 9 & GS-9 & $(\mathrm{M} X \mathrm{D}) \mathrm{X} \mathrm{M}$ & North Karnataka & 2674 \\
\hline 10 & GS-10 & (M X D) $-4-1-29-2$ & North Karnataka & 2415 \\
\hline 11 & GS-11 & (M X D)-4-2-1 & North Karnataka & 2536 \\
\hline 12 & GS-12 & (M X Sapnapalli) X M -4-5 & North Karnataka & 2327 \\
\hline 13 & GS-13 & (M X Sapnapalli)-4-5 & North Karnataka & 2279 \\
\hline 14 & GS-14 & M X Bommnahalli-4-1 & North Karnataka & 2204 \\
\hline 15 & GS-15 & M X Hottigudar-2 -4-5-2 & North Karnataka & 2732 \\
\hline 16 & GS-16 & (M X Hottigudar-2) X M -2-1 & North Karnataka & 2454 \\
\hline 17 & GS-17 & M X Hottigudar-2 -4-6 & North Karnataka & 2503 \\
\hline 18 & GS-18 & Phule mule X M -18-1 & North Karnataka & 2621 \\
\hline 19 & GS-19 & (IS26779 X M) X M -1-1-5-1 & North Karnataka & 2663 \\
\hline 20 & GS-20 & (IS26779 X M) X M -1-1-5-2 & North Karnataka & 2810 \\
\hline 21 & GS-21 & (IS26779 X M) X M -1-1-5-3 & North Karnataka & 2511 \\
\hline 22 & GS-22 & (IS26779 X M) X M -1-1-5-4 & North Karnataka & 2775 \\
\hline 23 & GS-23 & IS26779 X M -1-2-2-1 & North Karnataka & 2978 \\
\hline 24 & M-35-1 & Land race selection & North Karnataka and Maharashtra & 2549 \\
\hline 25 & Muguthi & Local check & North Karnataka and Maharashtra & 2196 \\
\hline
\end{tabular}

*M=M-35-1; D = DSV- 4

Stability of performance should be considered as an important aspect of yield trials. Researchers need a statistic that provides a reliable measure of stability or consistency of performance across a range of environments, particularly, one that reflects the contribution of each genotype to the total $\mathrm{G} \times \mathrm{E}$ interaction (Shukla, 1972). Keeping in view the present study was undertaken under post rain fed situation in four locations viz., Gulbarga, Raichur, Bellary and Malnoor to identify stable genotypes of sorghum for seed yield and its component traits.

\section{MATERIALS AND METHODS}

The 23 sorghum lines comprised of selection from local lines, advanced generation lines developed by crossing local, exotic lines with M-35-1 (Table 1). Lines were developed at Agricultural Research Station, Gulbarga, University of Agricultural Sciences, Raichur with inclusion of two varietal checks viz., M-35-1 and Muguthi. The trials were conducted in a Randomized Complete Block Design with three replications at four locations viz., Agriculture Research Stations Raichur, Gulbarga, Malnoor and Hagari receiving annual average rainfall of $729 \mathrm{~mm}, 549 \mathrm{~mm}, 573 \mathrm{~mm}$ and $534 \mathrm{~mm}$ representing diverse agro climatic conditions during rabi-2012-13. The plot size was 6 rows of $4 \mathrm{~m}$ length

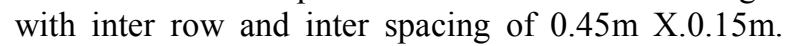
Each row was over planted later thinned to 1 plants/hill 15 days after emergence. $50 \mathrm{~kg}$ Nitrogen per hactor and $25 \mathrm{~kg}$ phosphorus per hactor of Diamonimum Phosphate was applied as basal fertilizer. All other crop cultural management practices were followed to raise successful crop.

Observations were recorded on five randomly selected plants in each replication in each environment in re- spect of 10 different characters viz., plant height $(\mathrm{cm})$, stem diameter $(\mathrm{cm})$, ear head length $(\mathrm{cm})$, ear head diameter $(\mathrm{cm})$, days to 50 per cent flowering, days to maturity, 100 seed weight $(\mathrm{g})$, fodder yield per plot $(\mathrm{kg})$, seed yield per plot $(\mathrm{kg})$, and lodging percentage. Stability analysis was carried out by using the stability model proposed by Eberhart and Russell (1966) using Window Stat Programme. According to them regression coefficient $\left(b_{i}\right)$ and deviation from regression ( $\left.\mathrm{S}^{2} \mathrm{di}\right)$ may be considered as two parameters for measuring the varietal phenotypic stability. These varieties with $\left(b_{i}\right)$ value which shall not significantly differ from unity $\left(b_{i}=1\right)$ and $\left(S^{2}\right.$ di) did not significantly differ from zero could be described as a stable variety.

\section{RESULTS AND DISCUSSION}

Pooled Analysis of variance of stability for different characters revealed that mean sum of squares due to genotypes was significant for ear head diameter, days to 50 per cent flowering, days to maturity and fodder yield. Variance due to $\mathrm{G} \times \mathrm{E}$ was significant for ear head diameter and fodder yield, indicating that the genotypes responded differently to the change in the environment (Table 2). Environmental linear component was significant for all traits except days to maturity, where as $\mathrm{G} \times \mathrm{E}$ (linear) interaction was non signify cant for most of the characters expect ear head diameter and fodder yield. Kher et al. (2008) in their studies revealed that $(\mathrm{G} \times \mathrm{E})$ linear component was non significant, while pooled deviation (non- linear component) was significant for green forage yield. The mean sum of square due to environment + (genotypes x environment) was significant for plant height, ear head length $(\mathrm{cm})$, ear head diameter $(\mathrm{cm})$, days to 50 per 
cent flowering, fodder yield per plot $(\mathrm{kg})$, seed yield er plot $(\mathrm{kg})$, and lodging percentage characters except stem diameter, days to maturity and 100 seed yield. Dudheech et al. (2007) concluded variance due environment, genotype $\times$ environment interaction and its linear components were found significant for test weight and number of grains per panicle. While nonlinear component was found significant for days to maturity and 100 seed weight. The influence of external environment and its interaction enhance the performance of genotypes. The MSS due to environment (linear) was significant for plant height, stem diameter, ear head length, ear head diameter, days to 50 per cent flowering, days to maturity, 100 seed weight, seed yield, fodder yield and lodging percentage indicating that environment effects were additive. Kishore and Singh (2004) revealed significant mean square due to environment indicated considerable differences among environments and their predominant effects on quantitative traits.

Eberhart and Russell (1966) defined a stable genotype as the one which showed high mean yield, regression co-efficient $\left(b_{i}\right)$ around unity and deviation from regression near to zero. Accordingly, the mean and deviation from regression of each genotype were considered for stability and linear regression was used for testing the varietal response. The estimates of stability parameters in respect of ten characters that had direct influence on genotypes performance is presented in Table 3. The genotype GS-3, GS-6 and GS-15 showed higher mean value with regression coefficient less than one and non-significant deviation from regression indicating wide adaptation to the entire environment with respect to plant height. Sharnabasappa (2009) indicated $\mathrm{G} \times \mathrm{E}$ interaction was significant for morphological characters suggesting that genotypes interacted significantly with environments. On the basis of stability parameters, BJB-28, BJB-42, BJB-133 and BJB143 were found to be stable for majority of the characters across the dates of sowing.

The genotypes GS-6, GS-11, GS-22 and GS-23 exhibited high mean value, deviation from regression was significant with close to zero values but regression coefficient showed around unity, indicates stable performance with respect to stem diameter. Genotypes GS -8, GS-16, GS-19, GS-20, GS-21, GS-22, GS-23, and and check variety Muguthi had high mean value with non-significant regression value check variety Muguthi had high mean value with non-significant regression value and non-significant deviation from regression indicating wider adoptability on tested environment with respect to ear head length. Patil et al. ( 1991) evaluated ten genotypes of sorghum (Sorghum bicolor) at five different environments during five monsoon seasons with respect to six yield and growth characters. Analysis of pooled data revealed significant genotype $\times$ environment interactions for all traits. Stability parameters indicated that best adapted genotype 
Table 3. Mean and stability parameters in advanced breeding lines of $S$. bicolour L. Moench.

\begin{tabular}{|c|c|c|c|c|c|c|c|c|c|c|c|c|}
\hline \multirow{2}{*}{$\begin{array}{l}\text { Traits } \\
\text { Genotypes }\end{array}$} & \multicolumn{3}{|c|}{ Plant height (cm) } & \multicolumn{3}{|c|}{ Stem diameter (cm) } & \multicolumn{3}{|c|}{ Ear head length $(\mathrm{cm})$} & \multicolumn{3}{|c|}{ Ear head Diameter $(\mathrm{cm})$} \\
\hline & mean & $\mathrm{S}^{2} \mathrm{di}$ & $\mathbf{b}_{\mathbf{i}}$ & mean & $S^{2}$ di & $\mathbf{b}_{\mathbf{i}}$ & mean & $\mathrm{S}^{2} \mathrm{di}$ & $\mathbf{b}_{\mathbf{i}}$ & mean & $\mathbf{S}^{2} \mathbf{d i}$ & $\mathbf{b}_{\mathbf{i}}$ \\
\hline GS-1 & 185.83 & $320.59 *$ & 0.85 & 1.542 & $0.024 * *$ & 2.708 & 12.76 & $1.21 *$ & 1.00 & 6.28 & -0.27 & 1.07 \\
\hline GS-2 & 189.20 & 28.91 & 1.19 & 1.481 & $0.030 * *$ & 0.928 & 10.93 & $1.94 * *$ & 0.81 & 5.50 & -0.14 & 0.88 \\
\hline GS-3 & 186.58 & -16.69 & 0.96 & 1.549 & 0.001 & 1.028 & 12.57 & $2.15^{* *}$ & 0.94 & 5.93 & -0.29 & $0.94 *$ \\
\hline GS-4 & 179.08 & -65.24 & 0.74 & 1.439 & 0.004 & 2.183 & 12.35 & -0.30 & 0.98 & 6.19 & -0.29 & $1.08 *$ \\
\hline GS-5 & 180.08 & -93.99 & 0.82 & 1.475 & -0.003 & 1.492 & 12.21 & 0.66 & 0.91 & 6.09 & -0.28 & $0.92 *$ \\
\hline GS-6 & 186.92 & -39.67 & 0.82 & 1.549 & $0.021 *$ & 0.044 & 12.25 & 0.72 & 0.94 & 6.44 & -0.13 & 1.14 \\
\hline GS-7 & 186.50 & -79.26 & 1.08 & 1.462 & -0.002 & -0.310 & 12.36 & -0.13 & 0.99 & 5.99 & -0.17 & 0.91 \\
\hline GS-8 & 185.40 & -32.59 & 1.03 & 1.517 & -0.001 & 1.846 & 12.67 & -0.29 & 1.01 & 6.27 & -0.25 & 0.95 \\
\hline GS-9 & 178.17 & -14.92 & 0.75 & 1.546 & 0.002 & 1.952 & 12.50 & -0.30 & 1.02 & 5.96 & -0.13 & 0.84 \\
\hline GS-10 & 178.32 & 85.05 & 0.72 & 1.547 & -0.002 & 1.353 & 13.57 & $1.79 * *$ & 1.12 & 6.66 & -0.27 & $1.27 *$ \\
\hline GS-11 & 175.58 & $216.90 *$ & 0.82 & 1.557 & $0.013 *$ & -1.224 & 14.43 & $6.28 * *$ & 1.23 & 6.94 & -0.23 & $1.43 *$ \\
\hline GS-12 & 179.33 & -62.23 & 0.77 & 1.500 & 0.003 & 1.467 & 12.31 & 0.50 & 1.00 & 5.48 & -0.29 & $0.80 *$ \\
\hline GS-13 & 171.42 & -71.65 & 0.82 & 1.528 & 0.008 & 1.431 & 12.05 & 0.11 & 0.94 & 5.71 & -0.29 & $0.94 *$ \\
\hline GS-14 & 183.17 & -46.15 & 1.20 & 1.528 & 0.001 & 0.150 & 11.87 & $2.13 * *$ & 0.90 & 5.40 & -0.20 & $0.77 *$ \\
\hline GS-15 & 183.17 & -39.21 & 0.90 & 1.551 & 0.006 & 0.091 & 12.43 & -0.14 & 0.97 & 5.86 & -0.28 & 0.91 * \\
\hline GS-16 & 181.67 & -10.68 & 1.20 & 1.423 & -0.002 & 0.484 & 12.72 & -0.04 & 1.00 & 6.29 & -0.06 & 0.95 \\
\hline GS-17 & 180.50 & -53.27 & 0.90 & 1.509 & -0.003 & $2.274 *$ & 12.75 & $1.96^{* *}$ & 0.97 & 6.60 & -0.19 & 0.99 \\
\hline GS-18 & 176.58 & -71.22 & 0.87 & 1.418 & 0.001 & 0.664 & 12.03 & -0.21 & 0.94 & 5.60 & -0.28 & $0.87 *$ \\
\hline GS-19 & 193.83 & -70.53 & 1.04 & 1.508 & 0.004 & 3.375 & 13.63 & -0.37 & 1.06 & 6.57 & 0.10 & 1.12 \\
\hline GS-20 & 189.67 & -56.29 & 1.44 & 1.423 & -0.003 & $-0.130 *$ & 12.71 & -0.03 & 1.02 & 6.39 & -0.29 & $1.12 *$ \\
\hline GS-21 & 185.50 & -74.52 & 1.26 & 1.433 & 0.006 & 1.156 & 13.24 & 0.21 & 1.08 & 6.32 & -0.28 & $1.15^{*}$ \\
\hline GS-22 & 185.00 & -19.14 & 1.02 & 1.556 & $0.023 * *$ & 0.765 & 13.26 & 0.05 & 1.05 & 6.58 & -0.22 & $1.23 *$ \\
\hline GS-23 & 178.08 & -41.20 & 0.96 & 1.561 & $0.017 * *$ & 0.171 & 13.12 & 0.66 & 1.05 & 5.90 & -0.20 & $0.78^{*}$ \\
\hline M 35-1 & 178.17 & 71.26 & 1.32 & 1.413 & -0.001 & 1.948 & 12.57 & 0.03 & 1.00 & 5.93 & -0.15 & 0.97 \\
\hline Muguthi & 189.80 & 9.97 & 1.51 & 1.453 & $0.018 * *$ & -0.847 & 12.94 & $2.51 * *$ & 1.08 & 5.88 & -0.29 & 1.00 \\
\hline $\begin{array}{l}\text { Population } \\
\text { mean }\end{array}$ & 182.70 & & & 1.490 & & & 12.64 & & & 6.10 & & \\
\hline \multicolumn{13}{|l|}{ Contd.... } \\
\hline Traits & \multicolumn{3}{|c|}{ Days to $50 \%$ flowering } & & \multicolumn{2}{|c|}{ Days to maturity } & \multicolumn{6}{|c|}{100 Seed weight (g) } \\
\hline Genotypes & \multicolumn{3}{|c|}{ mean $\quad S^{2} d i$} & $\mathbf{b}_{\mathbf{i}}$ & mean & $S^{2} d i$ & \multicolumn{2}{|r|}{$\mathbf{b}_{\mathbf{i}}$} & mean & $S^{2} d i$ & & $\mathbf{b}_{\mathbf{i}}$ \\
\hline GS-1 & 68.667 & 5.3 & & 1.053 & 110.17 & $12.82 * *$ & & 1.40 & 3.310 & $0.154 * *$ & & 0.061 \\
\hline GS-2 & 69.417 & 46. & $9 * *$ & 1.276 & 111.00 & $16.16^{* *}$ & & 3.91 & 3.452 & $0.367 * *$ & & 0.181 \\
\hline GS-3 & 68.667 & 12. & $5 * *$ & 1.362 & 112.00 & $17.51 * *$ & & 3.97 & 3.292 & $0.179 * *$ & & 0.529 \\
\hline GS-4 & 61.333 & 4.6 & & 0.295 & 105.83 & $7.83 * *$ & & 3.25 & 3.290 & $0.058 *$ & & -1.329 \\
\hline GS-5 & 63.500 & 31. & $4 * *$ & 0.388 & 107.25 & $41.75 * *$ & & 6.08 & 3.437 & $0.140 * *$ & & 3.288 \\
\hline GS-6 & 64.750 & 20. & $5 * *$ & 0.542 & 111.08 & $15.61 * *$ & & -0.55 & 3.283 & 0.011 & & 2.349 \\
\hline GS-7 & 63.333 & 2.5 & & 0.182 & 112.92 & $45.71 * *$ & & -2.54 & 3.116 & 0.019 & & 0.033 \\
\hline GS-8 & 62.667 & 6.8 & & 0.427 & 109.58 & $31.29 * *$ & & 6.34 & 3.005 & -0.001 & & 1.609 \\
\hline GS-9 & 63.667 & 3.1 & & 0.663 & 111.67 & $12.56 * *$ & & 4.56 & 3.253 & 0.017 & & 1.620 \\
\hline GS-10 & 63.667 & 2.8 & & 0.996 & 113.33 & $11.01 * *$ & & 2.23 & 3.166 & $0.301 * *$ & & 3.227 \\
\hline GS-11 & 56.083 & 38. & $9 * *$ & 0.464 & 98.67 & 3.95 & & 1.06 & 3.209 & 0.016 & & 1.835 \\
\hline GS-12 & 63.750 & -0.3 & & 0.937 & 111.25 & $6.09 *$ & & 0.33 & 3.038 & 0.015 & & -1.009 \\
\hline GS-13 & 64.083 & 1.5 & & 1.019 & 111.08 & 0.67 & & -0.60 & 3.328 & $0.075 * *$ & & 3.408 \\
\hline GS-14 & 73.333 & 43. & $4 * *$ & 1.593 & 115.75 & $80.53 * *$ & & -5.30 & 3.476 & -0.014 & & 0.480 \\
\hline GS-15 & 66.583 & 32. & $5 * *$ & 1.338 & 113.58 & $15.48 * *$ & & 0.57 & 3.183 & 0.009 & & 0.158 \\
\hline GS-16 & 63.333 & 11. & $5 * *$ & 0.813 & 109.17 & 2.45 & & 0.91 & 3.270 & 0.026 & & 0.484 \\
\hline GS-17 & 65.417 & 10. & $3 * *$ & 1.166 & 112.33 & $23.94 * *$ & & -0.51 & 3.103 & $0.053^{*}$ & & -0.030 \\
\hline GS-18 & 66.167 & 10. & $8 * *$ & 0.410 & 112.33 & 3.18 & & -2.72 & 3.063 & 0.023 & & 0.766 \\
\hline GS-19 & 67.833 & 3.0 & & 1.277 & 113.08 & $5.43 *$ & & 4.40 & 3.307 & $0.293 * *$ & & 3.237 \\
\hline GS-20 & 66.583 & 13. & $9 * *$ & 1.878 & 115.42 & $16.16^{* *}$ & & 0.13 & 3.146 & -0.011 & & $-1.368 *$ \\
\hline GS-21 & 69.167 & 41. & $8 * *$ & 1.407 & 115.75 & $43.75^{* *}$ & & -0.35 & 3.490 & $0.116 * *$ & & 0.550 \\
\hline GS-22 & 64.833 & 21. & $7 * *$ & 1.395 & 114.00 & -0.93 & & -1.86 & 3.413 & 0.022 & & 1.981 \\
\hline GS-23 & 63.917 & 9.5 & & 1.031 & 112.58 & $6.45^{*}$ & & -0.28 & 3.303 & $0.087 * *$ & & 0.015 \\
\hline M 35-1 & 66.917 & -0. & & $1.890^{*}$ & 116.67 & -1.22 & & 0.14 & 3.314 & -0.010 & & 1.354 \\
\hline Muguthi & 74.000 & 27. & $6 * *$ & 1.197 & 122.17 & $9.70 * *$ & & 0.44 & 3.148 & -0.017 & & 1.568 \\
\hline $\begin{array}{l}\text { Population } \\
\text { mean }\end{array}$ & 65.660 & & & & 111.90 & & & & 3.250 & & & \\
\hline
\end{tabular}


G. Girish et al. / J. Appl. \& Nat. Sci. 8 (1): 10 - 15 (2016)

\begin{tabular}{|c|c|c|c|c|c|c|c|c|c|}
\hline \multirow{2}{*}{$\begin{array}{l}\text { Traits } \\
\text { Genotypes }\end{array}$} & \multicolumn{3}{|c|}{ Fodder yield per plot (kg) } & \multicolumn{3}{|c|}{ Seed yield/ plot (kg) } & \multicolumn{3}{|c|}{ Lodging \% } \\
\hline & mean & $S^{2} d i$ & $\mathbf{b}_{\mathbf{i}}$ & mean & $S^{2} d i$ & $\mathbf{b}_{\mathbf{i}}$ & mean & $S^{2} d i$ & $\mathbf{b}_{\mathbf{i}}$ \\
\hline GS-1 & 9.867 & -0.192 & 0.894 & 1.708 & $0.254 * *$ & 0.876 & 10.239 & 1.800 & 1.079 \\
\hline GS-2 & 10.975 & 1.083 & 1.015 & 1.694 & $0.139 * *$ & 1.093 & 8.256 & 0.152 & 0.787 \\
\hline GS-3 & 10.108 & $1.429^{*}$ & 1.147 & 1.880 & -0.003 & $1.153^{*}$ & 10.312 & 9.947 & 1.631 \\
\hline GS-4 & 8.858 & 0.281 & 0.863 & 1.932 & -0.002 & 1.110 & 10.231 & 2.441 & 0.769 \\
\hline GS-5 & 10.025 & -0.395 & 0.887 & 1.813 & $0.152 * *$ & 0.960 & 10.666 & 7.720 & 1.498 \\
\hline GS-6 & 9.150 & 0.862 & 0.881 & 1.702 & $0.185 * *$ & 1.060 & 12.695 & 0.923 & 1.407 \\
\hline GS-7 & 9.958 & -0.384 & 0.995 & 1.658 & $0.029 *$ & 0.941 & 12.978 & -0.977 & 1.272 \\
\hline GS-8 & 9.575 & -0.488 & 0.949 & 1.870 & 0.006 & 1.063 & 12.024 & -2.029 & 1.471 \\
\hline GS-9 & 9.933 & 0.172 & 0.977 & 1.925 & $0.152 * *$ & 1.038 & 9.902 & -1.668 & 1.342 \\
\hline GS-10 & 9.008 & $6.087 * *$ & 0.826 & 1.739 & $0.153 * *$ & 0.777 & 11.743 & -1.091 & 1.808 \\
\hline GS-11 & 8.025 & 0.625 & 0.814 & 1.826 & $0.058 * *$ & 0.791 & 7.198 & -1.190 & 0.151 \\
\hline GS-12 & 9.092 & -0.530 & 1.020 & 1.675 & -0.002 & 0.965 & 8.409 & 4.769 & 0.950 \\
\hline GS-13 & 10.508 & -0.427 & 1.029 & 1.641 & $0.020 *$ & 0.941 & 10.648 & 7.036 & 0.646 \\
\hline GS-14 & 8.858 & -0.475 & 0.963 & 1.587 & $0.207 * *$ & 0.749 & 11.922 & $15.451^{*}$ & 1.465 \\
\hline GS-15 & 9.500 & -0.251 & 1.094 & 1.967 & 0.006 & 1.197 & 12.763 & -0.169 & 1.736 \\
\hline GS-16 & 9.283 & -0.495 & 0.985 & 1.767 & $0.031 *$ & 1.001 & 11.347 & -1.283 & 1.705 \\
\hline GS-17 & 10.333 & 0.900 & 1.187 & 1.802 & 0.117 & 1.071 & 12.010 & -2.389 & 1.664 \\
\hline GS-18 & 9.083 & $2.083^{*}$ & 0.774 & 1.887 & 0.010 & 0.953 & 12.332 & $16.726^{*}$ & 0.918 \\
\hline GS-19 & 9.275 & 0.355 & 0.893 & 1.917 & $0.110 * *$ & 1.097 & 13.289 & $11.180 *$ & 0.901 \\
\hline GS-20 & 9.917 & -0.504 & $1.111^{*}$ & 2.023 & $0.180 * *$ & 1.169 & 13.139 & -3.153 & 0.815 \\
\hline GS-21 & 10.925 & -0.091 & 1.232 & 1.808 & 0.086 & 1.008 & 11.785 & 1.305 & 0.496 \\
\hline GS-22 & 10.233 & -0.235 & 0.944 & 1.998 & -0.008 & 1.007 & 8.528 & -0.127 & 0.083 \\
\hline GS-23 & 9.867 & $1.279 *$ & 1.055 & 2.144 & 0.016 & 0.987 & 7.267 & -4.803 & $0.031 *$ \\
\hline M 35-1 & 10.267 & -0.143 & 1.166 & 1.835 & -0.003 & 1.051 & 13.511 & $24.821 * *$ & 0.162 \\
\hline Muguthi & 11.192 & -0.339 & $1.300^{*}$ & 1.581 & $0.042 * *$ & 0.943 & 12.598 & $30.263 * *$ & 0.215 \\
\hline $\begin{array}{l}\text { Population } \\
\text { mean }\end{array}$ & 9.750 & & & 1.810 & & & 11.030 & & \\
\hline
\end{tabular}

was SPV-346 for all characters, RSV 6 for fodder yield and RSV 10 for 1000 grain weight. Hybrid SPH 196 was stable and had the highest fodder yield (14.1 t/ha), grain yield (4.3 t/ha) and 1000 grain weight $(25.34 \mathrm{~g})$ under favourable environments. $\mathrm{CSH}-1$ and $\mathrm{CSH}-6$ was stable for days to maturity and response to poor environments. Mukri (2007) reported pooled analysis of variance revealed significant difference among the genotypes and environments for all the characters, indicating that genotypes and environments tested were diverse in nature. Genotype $\times$ environment interaction was significant for most of the characters suggesting, genotypes interacted significantly with environments. On the basis of stability parameters, DSH-4 and M-35-1 were promising genotypes for majority of the characters with higher mean performance across all the six dates of sowing. The genotypes GS-1, GS-4, GS-10, GS-11, GS-19, GS-20, GS-21 and GS-22 had regression coefficient more than one indicating lines were sensitive to environment but adapted to favourable environment with respect to ear head diameter. The genotypes GS4, GS-5, GS-6, GS-7, GS-8, GS-9, GS-10, GS-11, GS12 , GS-16 and GS-18 showing average stability having regression coefficient less than one with respect to 50 per cent flowering. The genotypes GS-6, GS-7, GS-12, GS-13, GS-14, GS-15, GS-17, GS-18, GS-20, GS-21, GS-22, GS-23 with both varietal checks M 35- 1 and Muguthi exhibiting regression coefficient less than one with high mean than the population mean indicating stable performance in unfavourable environment with respect to days to maturity. Narkhede et al. (1998) revealed the variance due o environment was significant for both grain and fodder yield and there was considerable interaction between cultivar and environment. The hybrid SPH 821 was stable for grain yield and SPH 792 was stable for fodder yield. Amith et al. (2007) indicated variance due to environment interaction and its linear components were significant for test weight and number of grains per panicle, while non linear genotypes exhibiting regression coefficient less than unity, maximum test weight was exhibited by genotypes SU 596 followed by SU 606 and SU 627 showing stable performance in unfavourable environment. In addition to maximum test weight, genotype SU 596 showed minimum days to maturity. For 100 seed weight the genotypes GS-14 and GS-16 showed regression value less than unity $(\mathrm{bi}<1)$, mean value higher than grand mean, with non-significant deviation from regression indicating that they were suitable for wide range of environments. The genotypes GS-2, GS13, GS-17, GS-20, and GS-21 showed higher mean values compared to grand mean, regression coefficient more than unity indicating the lines were suitable for favourable environmental condition with respect to fodder yield per plot. Narkhede et al. (1997) expressed linear and non -linear components played an important role in expression of both traits. The genotypes, CSV-15, SPV 1134, SPV 46 and SPV 1247 showed stable performance with high mean grain yield. The variety CSV-15 had high grain and fodder yield with good stability and 
responsive to environmental fluctuations. Significant genotype and environment interaction was observed for both traits and SPV 489 was stable for fodder yield. For seed yield per plot the genotypes GS-18 and GS23 exhibiting regression coefficient less than one with high mean value than the population mean value and non-significant deviation from regression coefficient indicating wider adoptability. The genotypes GS-6, GS -7, GS-8, GS-10, GS-14, GS-15, GS-16 and GS-17 were found high mean value and regression coefficient value more than unity indicating their sensitive to adopt favourable environment condition with respect to lodging percentage.

\section{Conclusion}

It is concluded that yield and its related traits may be taken into account while selecting/evaluating genotypes for stability performance across the environments. As for as 100 seed weight concern genotypes GS-14 and GS-16 were suitable for wide range of environments. Genotypes GS-18 and GS-23 were wider adopted for seed yield per plot. As for as fodder yield is concern genotypes GS-1, GS-5, GS-9, GS-22, GS23, M 35- 1 and Muguthi were adopted wider environments. Genotypes GS-8, GS-16, and GS-17 were wider adopted for ear head diameter. Genotypes GS-16, GS21, GS-22 and GS-23 were stable for ear head length. The genotypes GS-6 (High mean values of plant height, stem diameter, days to 50 per cent flowering and sensitive to lodging), GS-16 (High mean values of ear head length, ear head diameter, days to 50 per cent flowering, 100 seed weight and sensitive to lodging), GS-22 (High mean values of stem diameter, ear head length, days to maturity and fodder yield) and GS-23 (High mean values of stem diameter, ear head length, days to maturity and fodder yield and 100 seed yield) were most stable for mentioned characters with seed yield of $2364 \mathrm{~kg} / \mathrm{ha}, 2454 \mathrm{~kg}$ / ha, $2775 \mathrm{~kg} / \mathrm{ha}$ and $2978 \mathrm{~kg} / \mathrm{ha}$ over all four environments. This indicated that these lines were the potential ones for further use and these genotypes are recommended for farm trials in HyderabadKarnataka region, while further testing of the genotypes is required for further genetic manipulation.

\section{REFERENCES}

Allard, R.W. and Bradshaw, A.D. (1964). Implications of genotype- environment interactions in applied plant breeding. Crop Science, 4: 503- 507.

Amit, D., Shah, M.A. and Hemlata, S. (2007). Genotype environment interaction and stability analysis in sorghum. Indian Agriculturist, 51 (1/2): 13-16.

Anonymous, (2010). Final estimates of area, production and yield of important Agricultural crops in Karnataka. Directorate of Economics and Statistics, Pa 2-46.

Anonymous, (2013). Annual Report for 2012-13, All India Co-ordinated Sorghum Improvement Project, National Research Centre for Sorghum, Hyderabad, $62 \mathrm{pp}$.

Dudheech, A., Shah, M.A. and Sharma, H. (2007). Genotype environment interaction and stability analysis in sorghum. Indian Agriculturist, 51 (1/2):13-16

Eberhart, S.A. and Russell, W.A. (1966). Stability parameters for comparing varieties. Crop Science, 6: 36-40.

Kher, H. R., Parmar, H.P., Gangani, M.K. and Paramar, D.G. (2008). Stability analysis for fodder yield in forage sorghum (Sorghum bicolor (L.) Moench. Crop Research (Hissar), 36 (1/3):244-245

Kishore, N. and Singh, L. N. (2004). Stability for forage yield influencing traits in sorghum [Sorghum bicolor (L.) Moench] in montane. Indian Journal of Genetics and Plant Breeding, 64(1);71-72.

Kumar, V. and Chopra, A.K. (2013). Response of sweet sorghum after fertigation with sugar mill effluent in two seasons. Sugar Technology, DOI 10.1007/s12355-0130226-9

Mukri, G. (2007). Genetic studies on seed setting behaviour and other productivity traits in rabi Sorghum (Sorghum bicolor (L.) Moench). M.Sc. (Agri) Thesis, University Agriculture Sciences Dharwad, (India).

Narkhede, B. N., Shinde, M.S. and Patil, S.P. (1997). Stability performance of sorghum varieties for grain and fodder yields. Journal of Maharashtra Agriculture University, 22: 179-181.

Narkhede, B. N., Shinde, M.S. and Patil, S.P. (1998). Stability analysis in kharif sorghum hybrids. Journal of Maharashtra Agriculture University, 23: 299-301.

Patil, H. S., Narkhede, B. N. and Bapat, D.R. (1991). Stability parameters in sorghum. Journal of Maharashtra Agriculture University, 16: 13-15.

Sharanabasappa, (2009). Genetic studies in advanced breeding lines for Shootfly tolerance and productivity traits in rabi sorghum. M.Sc. (Agri) Thesis, University Agriculture Sciences Dharwad, (India). 